\title{
Change in Metabolic Syndrome Parameters With Antipsychotic Treatment in the CATIE Schizophrenia Trial: Prospective Data From Phase 1
}

\author{
Jonathan M. Meyer, M.D. [Assistant Professor] [Staff Psychiatrist], \\ Department of Psychiatry, University of California, San Diego \\ VA San Diego Healthcare System, jmmeyer@ucsd.edu \\ Vicki G. Davis, DrPH [Research Investigator], \\ Department of Biostatistics, Collaborative Studies Coordinating Center, University of North \\ Carolina at Chapel Hill, Bank of America Center, 137 E. Franklin Street, Suite 400, Chapel Hill, \\ NC 27514-4145, Vicki.Davis@mail.cscc.unc.edu \\ Donald C. Goff, M.D. [Associate Professor] [Director], \\ Department of Psychiatry, Harvard University \\ Schizophrenia Program, Massachusetts General Hospital, Freedom Trail Clinic - Lindemann \\ Mental Health Center, 25 Staniford St., Boston, MA 02114, goff@psych.mgh.harvard.edu \\ Joseph P. McEvoy, M.D. [Associate Professor], \\ Department of Psychiatry and Behavioral Sciences, Duke University, Clinical Research, John \\ Umstead Hospital, $100312^{\text {th }}$ Street, Butner, NC 27509, jpmcevoy@duke.edu
}

Henry A. Nasrallah, M.D. [Professor of Psychiatry and Neuroscience],

University of Cincinnati, 231 Albert Sabin Way, PO Box 670559, Cincinnati, OH 45267-0559,

NASRALHA@ucmail.uc.edu or hnasra2905@aol.com

Sonia M. Davis, DrPH [Director of Biostatistics],

Quintiles Inc., 5927 South Miami Blvd, Morrisville, NC 27560, sonia.davis@quintiles.com

Robert A. Rosenheck, M.D. [Professor of Psychiatry] [Director],

Epidemiology and Public Health, and the Child Study Center, Yale Medical School

Northeast Program Evaluation Center, VA Connecticut Health Care System, 950 Campbell Ave, West Haven, CT 06516, robert.rosenheck@yale.edu

Gail L. Daumit, M.D., M.H.S. [Associate Professor of Medicine, Epidemiology and Health Policy and Management],

Johns Hopkins Medical Institutions, 2024 East Monument Street, Suite 2-500, Baltimore, MD

21287,gdaumit@jhmi.edu

John Hsiao, M.D. [Chief],

Adult Psychopharmacology Intervention Program, National Institute of Mental Health, Bethesda, MD, jh23f@nih.gov

(C) 2008 Elsevier B.V. All rights reserved.

Corresponding Author: Jonathan Meyer, M.D., San Diego VAMC, 3350 La Jolla Village Drive (116A), San Diego, CA 92161, Email: jmmeyer@ucsd.edu, Tel 858 642-3570,Fax 858 642-6442.

Publisher's Disclaimer: This is a PDF file of an unedited manuscript that has been accepted for publication. As a service to our customers we are providing this early version of the manuscript. The manuscript will undergo copyediting, typesetting, and review of the resulting proof before it is published in its final citable form. Please note that during the production process errors may be discovered which could affect the content, and all legal disclaimers that apply to the journal pertain. 
Marvin S. Swartz, M.D. [Professor],

Department of Psychiatry and Behavioral Sciences, Duke University Medical Center, Box 3173,

Duke University Medical Center, Durham, NC 27710, swart001@mc.duke.edu

T. Scott Stroup, M.D., M.P.H. [Associate Professor], and

Department of Psychiatry, University of North Carolina at Chapel Hill, Campus Box 7160, Chapel

Hill, NC 27599-7160, scott_stroup@med.unc.edu

Jeffrey A. Lieberman, M.D. [Professor and Chairman]

Department of Psychiatry, Columbia University, Psychiatric Institute, 1051 Riverside Drive, New

York, NY 10032, JL2616@columbia.edu

\section{Abstract}

Background-The metabolic syndrome (MS) is associated with increased risk for diabetes mellitus and coronary heart disease, and is highly prevalent among schizophrenia patients. Given concerns over antipsychotic metabolic effects, this analysis explored MS status and outcomes in phase 1 of the CATIE Schizophrenia Trial.

Methods-The change in proportion of subjects with MS and individual criteria was compared between antipsychotic treatment groups, along with mean changes for individual criteria. Primary analyses examined subjects with fasting laboratory assessments at baseline and 3 months. Other analyses examined 3-month changes in MS status, waist circumference (WC), HDL cholesterol and blood pressure in all subjects, metabolic changes at the end of phase 1 participation (EOP), and repeated measures changes in HDL, blood pressure (BP) and WC over phase 1.

Results-At 3 months, there were no significant between-drug differences for the change in proportion of subjects meeting MS status or individual MS criteria in the smaller fasting cohort $(n=281)$ or for those meeting criteria for parameters not dependent on fasting status (BP, HDL, WC) among all subjects $(n=660)$. Among all subjects whose MS status could be determined at 3 months ( $\mathrm{n}=660$ ), MS prevalence increased for olanzapine (from $34.8 \%$ to $43.9 \%$ ), but decreased for ziprasidone (from $37.7 \%$ to $29.9 \%$ ) ( $\mathrm{p}=.001$ ). Although effect sizes varied across subgroups, at 3 months olanzapine and quetiapine had the largest mean increase in waist circumference $(0.7$ in for both) followed by risperidone ( $0.4 \mathrm{in})$, compared to no change for ziprasidone ( $0.0 \mathrm{in}$ ) and a decrease in waist circumference for perphenazine $(-0.4 \mathrm{in})$. Olanzapine also demonstrated significantly different changes in fasting triglycerides at 3 months $(+21.5 \mathrm{mg} / \mathrm{dl})$ compared to ziprasidone $(-32.1 \mathrm{mg} / \mathrm{dl})$. EOP exposure data was obtained, on average, nine months from baseline for all metabolic variables. Results from EOP and repeated measures analyses were consistent with those at 3 months for mean changes in WC and fasting triglycerides, but between group differences emerged for HDL and SBP.

Conclusions-This large non-industry sponsored study confirms the differential metabolic effects between antipsychotics. Clinicians are advised to monitor all metabolic parameters, including WC, HDL and serum triglycerides, during antipsychotic treatment.

\section{Keywords}

antipsychotic; schizophrenia; metabolic syndrome; lipids; HDL; triglycerides; waist circumference; central adiposity

\section{Introduction}

The metabolic syndrome concept has been in around in several forms and with various names (syndrome $\mathrm{X}$, the dysmetabolic syndrome, the deadly quartet, the GHO syndrome \{glucose intolerance, hypertension, obesity\}) for 20 years (Reaven, 1988). In certain 
susceptible individuals, weight gain results not only in compensatory hyperinsulinemia, but co-occurring hypertension, atherogenic dyslipidemia (decreased high density lipoprotein cholesterol, elevated triglycerides), and increased levels of prothrombotic proteins and inflammatory markers. These metabolic parameters define a continuum of risk, such that those individuals who have more features of this syndrome appear more greatly predisposed to type 2 diabetes mellitus (DM) (de Vegt et al., 2001) and cardiovascular (CV) disease (Ford, 2004).

Since the publication of the Clinical Antipsychotic Trials of Intervention Effectiveness (CATIE) Schizophrenia Trial baseline metabolic syndrome data in 2005 (McEvoy et al., 2005), two important trends have emerged in the worldwide metabolic syndrome literature. In late 2005, the International Diabetes Federation modified the metabolic syndrome criteria previously elaborated by the National Cholesterol Education Program (NCEP) (Expert Panel on Detection Evaluation and Treatment of High Blood Cholesterol in Adults, 2001), with an emphasis on abdominal adiposity as a necessary condition that must be met, in addition to a minimum of 2 of the other 4 criteria (see Table 1) (Alberti et al., 2006). While this newer definition asserts the primacy of central obesity in the conceptualization of metabolic syndrome, it is not entirely clear that it yields greater predictive power for future CV events than NCEP criteria (Assmann et al., 2007). The varying definitions have also fueled an ongoing debate in the recent literature over the value of the metabolic syndrome concept (Kahn et al., 2005; American Heart Association et al., 2005; Reaven, 2005). Embedded in this discussion are concerns over the absence of a unifying pathophysiological mechanism that encompasses all criteria, and the finding that the syndrome diagnosis itself confers no greater predictive value for assessing $\mathrm{CV}$ risk than traditional estimating algorithms (Wannamethee et al., 2005). Nonetheless, there is a strong association between the number of metabolic syndrome criteria met and increased risk of CHD (Girman et al., 2005); moreover, the concept is of value by highlighting clinical findings that, in isolation, may not generate significant attention, and are associated with future risk for DM and CHD (Lorenzo et al., 2007). Hypertension and low levels of high density lipoprotein (HDL), the so-called "good" cholesterol, have long been recognized as predictors of CHD risk (Barter et al., 2007), but the NCEP metabolic syndrome definition provided clinicians a useful concept for understanding the association between central adiposity, serum triglycerides, insulin resistance and DM risk, and the need for routine monitoring of waist circumference (WC) (as a marker of central adiposity) and triglycerides (Jeppesen et al., 1998; Expert Panel on Detection Evaluation and Treatment of High Blood Cholesterol in Adults, 2001).

Cardiovascular disease remains one of the primary causes of mortality among patients with severe mental illness, with standardized mortality ratios approximately two times greater than the general population (Saha et al., 2007). Baseline data from the CATIE Schizophrenia Trial and other large cohorts have underscored the public health problem of high CHD risk (Goff et al., 2005) and the increased prevalence of prediabetic states such as the metabolic syndrome in patients with schizophrenia (Cohn et al., 2004; McEvoy et al., 2005; Hagg et al., 2006; Saari et al., 2005; De Hert et al., 2006; Bobes et al., 2007; Srisurapanont et al., 2007). Multiple cross-sectional studies have shown that the schizophrenia population has a prevalence of type $2 \mathrm{DM}$ and metabolic syndrome twofold greater than the general population (Bushe and Holt, 2004; Cohn et al., 2004; McEvoy et al., 2005; De Hert et al., 2006; Bobes et al., 2007). Comparative analysis of 689 subjects entering the CATIE Schizophrenia Trial and demographically matched individuals from the general population revealed odds ratios for meeting NCEP-defined metabolic syndrome of 2.4 and 3.5 for men and women with schizophrenia (respectively) (McEvoy et al., 2005). There was also greater prevalence of every metabolic syndrome criterion except fasting glucose for men, illustrating the point that changes in fasting glucose are relatively late markers of diabetes risk. 
While lifestyle factors such as smoking are significant contributors to CV risk for patients with schizophrenia (Goff et al., 2005), one source of metabolic risk derives from the treatment itself. The finding of differential metabolic profiles for atypical antipsychotics was first noted in early retrospective literature (Meyer, 2002), but confirmed by numerous prospective studies (Newcomer, 2005). The parameters most greatly influenced by treatment with metabolically offending medications are weight, serum triglycerides and measures of glycemic control, with substantially less effect on serum HDL or blood pressure (Newcomer, 2005). In 2004, representatives of the American Diabetes Association, American Psychiatric Association and other associations for the study of endocrine issues and obesity published a consensus report (the ADA/APA Consensus paper) calling attention to the relatively greater risk for weight gain, hyperlipidemia and hyperglycemic states imposed by exposure to olanzapine and clozapine, and also for strict monitoring of metabolic outcomes in all patients during atypical antipsychotic therapy (American Diabetes Association, 2004).

The bulk of the antipsychotic metabolic outcomes data derives from industry sponsored studies, where subject selection may specifically exclude individuals with medical comorbidities. The broad recruitment strategy of the CATIE Schizophrenia Trial, its multisite design and large sample size, offers a unique opportunity to explore the differential impact of antipsychotics on the metabolic syndrome in a sample that more closely approximates the expected medical and functional status of chronic patients with schizophrenia in the US. Given the known proclivities for metabolic disturbance among the antipsychotics in phase 1, the a priori hypothesis for this analysis is that there would be significant between-drug differences in their impact on the components of the metabolic syndrome.

\section{Methods}

\section{Study Setting, Design and Subjects}

The recruitment criteria for the CATIE Schizophrenia Trial and enrollment methods have been previously described (Stroup et al., 2003). Briefly, the CATIE Schizophrenia Trial is a national, multisite, NIMH-sponsored prospective trial, conducted between January 2001 and December 2004, examining antipsychotic effectiveness in patients with schizophrenia ages 18-65. First episode patients and those with a diagnosis of schizoaffective disorder were excluded. The primary outcome measure was all cause antipsychotic discontinuation, but the CATIE design broadly assessed metabolic, symptom, economic, neurocognitive and functional outcomes. Institutional Review Board approval was obtained at each of the 57 sites, and subjects voluntarily enrolled after having been provided informed consent in verbal and written form. Baseline demographic information collected on each subject included age, gender, NIH designations of ethnicity and race, and current antipsychotic medication; however, neither duration of current antipsychotic regimen, nor historical information regarding duration of prior antipsychotic trials was obtained. Identifying information was removed from databases prior to analysis to preserve subject confidentiality. Data from one site (33 patients) were excluded from all analyses because of concerns about their integrity.

In phase 1, subjects were initially randomized to receive olanzapine, perphenazine, quetiapine or risperidone under double-blind conditions and followed up to 18 months, or until the subject discontinued the medication. Two hundred and thirty-one subjects with baseline tardive dyskinesia (TD) were excluded from assignment to perphenazine. Ziprasidone was added to the protocol in 2002 after $40 \%$ of the sample had been enrolled, thus creating 4 separate randomization cohorts for analysis based upon TD status, and whether enrollment occurred prior to or after ziprasidone was available. Subjects who 
discontinued medication in phase 1 prior to 18 months could be followed in subsequent phases of the study ( 2 and 3 ). The mean daily medication doses in phase 1 were: olanzapine $20.1 \mathrm{mg}$, perphenazine $20.8 \mathrm{mg}$, quetiapine $543.4 \mathrm{mg}$, risperidone $3.9 \mathrm{mg}$, ziprasidone 112.8 $\mathrm{mg}$ (Lieberman et al., 2005).

\section{Measures}

CATIE subjects were asked to present in a fasting state for laboratory evaluations, but there was a significant range recorded for time since last meal. Published data support the use of 8 hours or more since last meal as an appropriate definition of fasting (Troisi et al., 2000), so this was used as the cutoff for determination of fasting status. The definition of the metabolic syndrome itself, derived from the NCEP definition, involves satisfying 3 or more of the criteria noted in Table 1, and is the one most commonly used in recent U.S. prevalence studies (Grundy et al., 2004). Blood pressure was performed as a single, seated determination, and WC measured at the narrowest point. All metabolic laboratory measures were performed at the Quintiles central laboratory.

For those subjects whose baseline laboratory values were not obtained in a fasting state by the definition above, we sought to classify metabolic syndrome status using the available data in order to enlarge the pool of subjects with which to assess change in metabolic syndrome status. Blood pressure, WC and HDL criteria are not influenced by fasting status, and could be accurately assessed in nonfasting subjects. Both serum glucose and triglycerides are affected by recent food ingestion, and present some challenges for interpretation. The glucose criterion was considered met for the nonfasting subjects if they were prescribed hypoglycemic medications or insulin, or if the random glucose value was $\geq$ $200 \mathrm{mg} / \mathrm{dl}$, meeting the ADA cut point for DM using random glucose values (American Diabetes Association, 2007). The glucose criterion was considered not met if the random (nonfasting) serum glucose was less than $100 \mathrm{mg} / \mathrm{dL}$. Similarly, the triglyceride criterion was considered not met if the random serum value was less than $150 \mathrm{mg} / \mathrm{dl}$. Random glucose values in the range of 100-199 mg/dl (in those not taking antidiabetic medications), and random triglyceride values of $150 \mathrm{mg} / \mathrm{dl}$ or greater were not counted positively or negatively for the respective criteria. Laboratory measures were collected at baseline and 3, 6,12 , and 18 months. Blood pressure and WC were obtained at screening, 1, 3, 6, 9, 12, 15 and 18 months.

\section{Analyses}

The primary analysis was conducted in subjects with fasting laboratory values at baseline and the primary endpoint (the fasting cohort). The endpoint for this analysis was the 3month visit, a point that permits maximal retention of subjects in all treatment arms, while also providing a clinically meaningful time frame for the demonstration of differential metabolic effects. These analyses examined mean changes in metabolic syndrome variables and the proportion meeting metabolic syndrome criteria, and each of the individual criteria. Secondary analyses were performed using 3-month, and end of phase (EOP) data in all subjects for whom metabolic data was available. For those subjects who did not remain on the randomized medication for 18 months, the EOP data for phase 1 is from the last visit prior to switching or discontinuation. Change from baseline WC, HDL and systolic and diastolic blood pressure in phase 1 was also compared across treatment groups with a mixed model. Change in fasting glucose or triglycerides were not assessed over 18 months with a mixed model due to the paucity of fasting samples at each time point.

\section{Statistics}

Treatment groups were compared for change from baseline in the proportion meeting MS status or individual syndrome criteria by a mean-score chi square test for ordinal data (4 df). 
For continuous outcomes, unadjusted mean changes were examined using a $4 \mathrm{df}$ Analysis of Variance (ANOVA). If this initial analysis yielded an overall treatment group difference, subsequent pairwise comparisons were performed. The p-values from the 10 between-drug pairwise comparisons for each variable were evaluated using a Bonferroni correction to maintain the overall Type I error rate of .05 , yielding an alpha of $.05 / 10=.005$ as the threshold for significance. All variables were examined for normality of distribution, and both change in glucose and triglycerides had a small number of extreme values (six and five respectively) defined as being greater than 3 standard deviations from the mean. Extreme values were addressed using a Winsorization method, by which the $\mathrm{n}$ largest and smallest data points are replaced by the $(n+1)$ th largest and smallest values for change in glucose and triglycerides (Dixon, 1960).

An Analysis of Covariance (ANCOVA) was also used to adjust for demographic and other baseline measures that were found be associated with the change in metabolic syndrome variables. Variables considered for inclusion in the ANCOVA models included the baseline value of the dependent change variable, age, gender, race, ethnicity, and duration of treatment (for the EOP analyses only). Ziprasidone was added as a treatment option after recruitment of approximately $40 \%$ of the phase 1 sample, so analyses were also examined to determine whether the sample enrolled after the availability of ziprasidone differed from that previously entered (i.e. a ziprasidone cohort effect), and whether prior TD was a factor. Interactions between treatment group and significant covariates were explored for each model. If an interaction was identified, treatment groups were compared within levels of the covariate using additional ANCOVA models.

The mixed model analysis of WC, HDL and blood pressure outcomes includes terms representing the baseline value of the dependent variable, time (treated as a classification variable), other covariates determined to be important in the ANCOVA models, and terms representing baseline-by-time and treatment-by-time interactions. The baseline-by-time term adjusts for baseline differences in characteristics of patients who dropped out early, and are less well represented at later time points. A random subject effect and a spatial power covariance structure were used to adjust standard errors for the correlation of observations from the same individual.

\section{Results}

Among the 933 subjects with data at baseline and 3 months, there were only 281 subjects with fasting laboratory measures at both time points (the fasting cohort). Table 2 shows the baseline demographics of all subjects, and the subject cohorts used in the primary 3-month analyses (e.g. fasting, all classifiable). Initial demographic comparison of the fasting cohort and nonfasting subjects indicated no significant between group differences. The 3-month outcome analysis of metabolic syndrome status and proportion that met each criterion in the fasting cohort showed no differences between treatments (Table 3). Among the 933 subjects who had baseline and 3-month data, the metabolic syndrome status could be classified for 660. In this larger all classifiable (AC) group, the 3-month analysis of metabolic syndrome status (Table 4) did reveal significant between group differences in the proportion changing metabolic syndrome status between olanzapine $(+9.1 \%$ from baseline) compared to ziprasidone $(-7.8 \%)(\mathrm{p}=.001)$. An examination of the change from baseline to 3 months in the proportion meeting the WC, blood pressure and HDL criteria found no significant between group differences (Table 4a).

The two medications most represented at CATIE phase 1 baseline were olanzapine (22\%) or risperidone (19\%). An analysis explored the effect on MS status and individual criteria of staying on these particular medications or being switched from other treatments to these 
medications in phase 1, but found no significant differences in the fasting cohort (Supplemental Data Table A), or the larger AC cohort (Supplemental Data Table B).

Covariate analyses of mean changes in individual parameters at 3 months (Table 5) found significant between group differences in $\mathrm{WC}(\mathrm{p}<.001)$ and fasting triglycerides $(\mathrm{p}=.016)$. Estimated increase in WC was greatest for olanzapine and quetiapine $(+0.7 \mathrm{in}, \mathrm{SE}=0.2$ for both), followed by risperidone ( $+0.4 \mathrm{in}, \mathrm{SE}=0.2)$ and ziprasidone $(+0.0 \mathrm{in}, \mathrm{SE}=0.2)$, with only perphenazine showing a mean decrease $(-0.4 \mathrm{in}, \mathrm{SE}=0.2)$. Estimated change in fasting triglycerides ranged from $+21.5 \mathrm{mg} / \mathrm{dl}$ ( $\mathrm{SE}=10.3)$ for olanzapine to $-32.1 \mathrm{mg} / \mathrm{dl}(\mathrm{SE}=15.7)$ for ziprasidone, with between group differences significant for olanzapine vs. ziprasidone $(\mathrm{p}=.005)$. No significant differences between treatments were found for mean changes in BP, HDL and fasting glucose.

An interaction between 3-month change in WC and both age and baseline WC was identified. Younger and thinner subjects experienced more deleterious changes than older and more centrally obese individuals (Figure 1). For subjects with baseline WC below the median (39 inches), between group comparison was significant for olanzapine vs. perphenazine ( $\mathrm{p}=.001)$, and olanzapine vs. ziprasidone $(\mathrm{p}=.001)$. For subjects with baseline $\mathrm{WC}$ at or above the median, between group comparison was significant for olanzapine vs. perphenazine ( $\mathrm{p}=.001)$, quetiapine vs. perphenazine $(\mathrm{p}<.001)$, risperidone vs. perphenazine $(\mathrm{p}=.001)$. Among subjects with baseline age below the median (42 years), between group comparison was significant for olanzapine vs. perphenazine ( $\mathrm{p}<.001)$, quetiapine vs. perphenazine $(\mathrm{p}=.004)$, risperidone vs. perphenazine $(\mathrm{p}=.003)$, but was significant only for quetiapine vs. perphenazine $(\mathrm{p}=.002)$ in those with baseline age $\geq 42$. A significant interaction between treatment and gender was identified for 3-month change in HDL, and a ziprasidone cohort effect was found for the 3-month change in HDL and fasting glucose; however, further analysis revealed these interactions to be unimportant to between group treatment comparisons.

As seen in the 3-month results, analysis of change to the end of phase 1 (EOP) identified an interaction between treatment group and baseline values for WC. Thinner subjects at baseline had larger increases in WC, and olanzapine exposure was associated with greater increases versus every other medication among these subjects ( $p=.001 \mathrm{vs}$. risperidone, $p<$. 001 vs. quetiapine, ziprasidone, and risperidone). For subjects with baseline WC $\geq 39$ inches, only those on olanzapine and quetiapine did not have decreases in central adiposity, and this was significantly different for both agents versus perphenazine ( $\mathrm{p}<.001$ vs. olanzapine, $\mathrm{p}=.003$ vs. quetiapine), and for olanzapine vs. risperidone ( $\mathrm{p}=.003)$. The significant difference in fasting triglycerides between olanzapine and ziprasidone at 3 months was also seen in the EOP analysis ( $\mathrm{p}=.003)$, but only for subjects at or above the median triglyceride level $(148 \mathrm{mg} / \mathrm{dl})$.

With the longer mean time of exposure for the EOP analysis compared to the 3-month data, significant between-group differences in HDL and SBP emerged. Perphenazine showed disparate effects on HDL with significantly favorable impact among whites (mean increases) compared to olanzapine and quetiapine, but both olanzapine and perphenazine were associated with a deleterious impact in non-whites when compared to ziprasidone. For subjects with baseline SBP at or above the median $(122 \mathrm{~mm} \mathrm{Hg})$, SBP decreased for all drug groups, and the difference was significant ( $\mathrm{p}=.001)$ between risperidone $(-9.0 \mathrm{~mm} \mathrm{Hg}$, $\mathrm{SE}=1.1)$ and olanzapine $(-3.6 \mathrm{~mm} \mathrm{Hg}, \mathrm{SE}=1.2)$ Among subjects with fasting triglyceride levels at or above the median $(148 \mathrm{mg} / \mathrm{dl})$, all medications decreased fasting triglyceride levels except for olanzapine $(+5.2 \mathrm{mg} / \mathrm{dl}, \mathrm{SE}=17.4)$, and this was significantly different than ziprasidone $(-96.4 \mathrm{mg} / \mathrm{dl}, \mathrm{SE}=28.5)(\mathrm{p}=.003)$. 
Repeated measures mixed model analysis of WC showed an interaction with baseline value (Figures $2 \mathrm{a}$ and $2 \mathrm{~b})$. Olanzapine caused greater increases in central adiposity $(+1.9$ inches) against all other medications (range +.3 inches [ziprasidone] to +1.1 inches [ripseridone]) for subjects with WC below the median, and perphenazine ( -1.0 inches) was superior to both olanzapine $(+.2$ inches; $\mathrm{p}<.001)$ and quetiapine $(0.0$ inches; $\mathrm{p}=.001)$ for those with baseline WC above the median. For those subjects with baseline WC at or above the median, only the olanzapine-exposed cohort did not experience an adjusted mean decrease in WC.

Results of mixed model analyses for HDL cholesterol and systolic blood pressure were consistent with findings from the EOP analyses. For HDL, there remained a significant effect of race on outcomes, with perphenazine causing increases among whites $(+3.1 \mathrm{mg} / \mathrm{dl})$ that was statistically different than olanzapine, risperidone and quetiapine. Among nonwhites perphenazine decreased HDL $(-1.0 \mathrm{mg} / \mathrm{dl})$, and this change was different than for ziprasidone $(+3.6 \mathrm{mg} / \mathrm{dl} ; \mathrm{p}=.002)$, as was the comparison between olanzapine $(-1.4 \mathrm{mg} / \mathrm{dl})$ and ziprasidone ( $\mathrm{p}<.001)$. Changes in diastolic BP were not significant, but systolic BP was influenced by baseline value. There was one significant between group difference (perphenazine $+4.2 \mathrm{~mm} \mathrm{Hg}$ vs. ziprasidone $+8.6 \mathrm{~mm} \mathrm{Hg}, \mathrm{p}=.005$ ) for subjects with baseline SBP below the median value $(122 \mathrm{~mm} \mathrm{Hg})$. Among those with baseline SBP at or above the median value, change for olanzapine was significantly different than risperidone ( -4.6 vs. $-8.4 \mathrm{~mm} \mathrm{Hg}$; $\mathrm{p}=.003)$, as seen in the EOP analysis, but also for olanzapine vs. ziprasidone ( -4.6 vs. $-9.1 \mathrm{~mm} \mathrm{Hg}$; $\mathrm{p}=.005$ ).

\section{Discussion}

The CATIE Schizophrenia Trial represents the largest randomized, double-blind nonindustry sponsored antipsychotic study. The results presented here provide further confirmation of differences in metabolic impact among atypical antipsychotic medications, and those parameters mostly influenced, even during brief periods of exposure. Adverse changes in any of the metabolic syndrome components incurs additive risk for future DM and CHD, but the association between insulin resistance, serum triglycerides and central adiposity are particularly strong (Mayer-Davis et al., 2001; McLaughlin et al., 2003).

The impact of olanzapine on metabolic outcomes has been documented previously, but these data indicate that within 3 months of exposure to olanzapine there was a significant increase in the proportion of subjects who met metabolic syndrome criteria, while those switched to ziprasidone show decreased MS prevalence. Even among subjects with clinical findings associated with insulin resistance, whether based on baseline WC or serum triglycerides, olanzapine exposure was associated with further deterioration in metabolic status. Continued worsening of metabolic profiles has been shown during long-term clozapine exposure (Henderson et al., 2005), but the repeated measures and EOP data indicate that olanzapine may share this propensity. This is an important consideration for the monitoring of subjects during olanzapine treatment, especially for patients who already have evidence of metabolic dysfunction, and for the initial choice of antipsychotic treatment.

This is also the largest study to indicate that quetiapine, when used in full therapeutic antipsychotic dosages, may have significant effects on central adiposity. The APA/ADA Consensus paper published in 2004 indicated that, with the information available as of November 2003, quetiapine and risperidone may have similar metabolic profiles, and were more benign than clozapine or olanzapine (American Diabetes Association, 2004). Henderson's subsequent analysis of insulin sensitivity in patients on quetiapine $(n=7)$ or olanzapine $(n=8)$ found olanzapine markedly worse than normal controls $(n=9)$, but no significant difference versus quetiapine, or for quetiapine versus controls, though insulin sensitivity inversely correlated with quetiapine dose $(\mathrm{p}=.0001)$ (Henderson et al., 2006). 
The data presented here suggest that quetiapine has significant adverse effects on HDL (in white subjects) and adiposity in a manner not seen with risperidone, despite not having a greater impact on serum glucose. As expected from earlier studies (Weiden et al., 2007), ziprasidone did not significantly worsen and often improved metabolic indices, particularly central adiposity and triglycerides.

The accumulated literature on antipsychotic metabolic effects has noted less impact on blood pressure than other metabolic parameters, and this is confirmed here. Weight gain is associated with hypertension, but over the time frame of this study this effect on BP was not evident. The absence of a significant signal for HDL changes in other antipsychotic studies may have been the result of limited duration of exposure and smaller sample sizes, since the EOP results here reveal a deleterious impact of olanzapine and quetiapine on serum HDL in whites, and significant improvement in HDL with ziprasidone in non-whites. Whether the failure to find a significant impact of ziprasidone on HDL among whites, and olanzapine or quetiapine on HDL in non-whites, is a function of type II error, or represents a unique interaction between antipsychotic properties and biology is unknown. The perphenazine data, however, suggests that the concept of differential metabolic effects between antipsychotics on the basis of race is one worth exploring.

Early studies showed that low potency phenothiazines were capable of causing weight gain, elevated triglycerides and hyperglycemia, while high potency agents appeared metabolically neutral (Meyer and Koro, 2004), but there is virtually no information on medium potency agents such as perphenazine published in the past 40 years. The data from CATIE phase 1 are clear that perphenazine, a phenothiazine whose affinity for dopamine $\mathrm{D}_{2}$ receptors is one fifth that of haloperidol, appears to be metabolically neutral, with effects that are similar to ziprasidone. The one exception to this profile was the HDL decreases in non-whites, an unexpected result that provides further impetus for examining the impact of race and other biological markers of metabolic risk, on antipsychotic metabolic outcomes.

The lack of significant between group differences for glucose should not reassure clinicians that there are no differences in the risk for future type $2 \mathrm{DM}$ between antipsychotic agents. The development of DM is the result of a long-term process, evolving over 10-20 years, that starts with insulin resistance, and progresses as patients experience $\beta$-cell failure. Changes in serum glucose may not be robust during shorter time frames, but the association between insulin resistance, WC and serum triglycerides raises concern that medications which impact markers of insulin resistance are hastening the onset of this metabolic process.

One limitation of the present study centers on the fact that insulin sensitivity was not directly measured, so we are left to infer changes in insulin resistance risk from associated parameters such as WC or serum triglyceride levels. Direct measurement of insulin sensitivity requires sophisticated, time consuming and expensive methods (e.g. euglycemic clamp, frequently sampled intravenous glucose tolerance testing) beyond the scope of this trial, and also involves controls for sources of variation such as time of day or phase of menstrual cycle. Duration of baseline antipsychotic exposure was also not recorded, a factor that becomes relevant primarily if those with longer exposure to more metabolically offending medications were randomized inequitably between various medications arms. Lastly, WC is used as a marker of visceral adiposity, rather than employing direct dexascan-, CT- or MRI-based determination of visceral fat mass. While imaging methods yield greater precision, this comes at greater cost; moreover, clinical studies have shown that anthropometric measures of central adiposity are highly correlated with direct determination (Snijder et al., 2002), and thus can be recommended for routine clinical purposes. 
An underlying purpose behind the identification of individuals who meet criteria for metabolic syndrome is to prevent the conversion from prediabetes to overt DM, since type 2 $\mathrm{DM}$ is considered a predictor of future myocardial infarction risk equivalent to having a diagnosis of CHD (Expert Panel on Detection Evaluation and Treatment of High Blood Cholesterol in Adults, 2001). Patients with schizophrenia have high mortality from natural causes, especially CHD (Saha et al., 2007), and are clearly susceptible to metabolic dysfunction and type $2 \mathrm{DM}$, yet some individuals may respond better to medications that carry greater metabolic burdens. These data provide further support for the use of all components of metabolic syndrome, not just serum glucose, in the routine health monitoring of antipsychotic exposed patients in order to forestall the onset of DM and increased CHD risk (Meyer and Nasrallah, 2003; Marder et al., 2004). Emerging data may identify the mechanisms by which metabolically offending medications decrease insulin sensitivity (Houseknecht et al., 2007), but, for the present, clinicians are advised to be judicious in the use of medications with potential metabolic liabilities, to be mindful of the pattern of metabolic problems seen with antipsychotics, especially clozapine, olanzapine and quetiapine, and to routinely monitor for all metabolic syndrome criteria, with particular attention to WC, serum HDL and triglycerides.

\section{Acknowledgments}

The CATIE Trials were supported by National Institute of Mental health (NIMH) grant \#N01MH90001. We wish to acknowledge the contributions of all investigators, study personnel and subjects from all of the CATIE Schizophrenia Trial sites.

\section{Bibliography}

Alberti KGMM, Zimmet P, Shaw J. Metabolic syndrome--a new world-wide definition. A Consensus Statement from the International Diabetes Federation. Diabetic Medicine. 2006; 23:469-480. [PubMed: 16681555]

American Diabetes Association. Diagnosis and classification of diabetes mellitus. Diabetes Care. 2007; 30(Suppl 1):S42-S47. [PubMed: 17192378]

American Diabetes Association, American Psychiatric Association, American Association of Clinical Endocrinologists, North American Association for the Study of Obesity. Consensus Development Conference on Antipsychotic Drugs and Obesity and Diabetes. Journal of Clinical Psychiatry. 2004; 65:267-272. [PubMed: 15003083]

Grundy SM, Cleeman JI, Daniels SR, Donato KA, Eckel RH, Franklin BA, Gordon DJ, Krauss RM, Savage PJ, Smith SC Jr, Spertus JA, Costa F. American Heart Association, National Heart Lung and Blood Institute. Diagnosis and management of the metabolic syndrome. An American Heart Association/National Heart, Lung, and Blood Institute Scientific Statement. Executive summary. 2005; 13:322-327. Cardiology in Review.

Assmann G, Guerra R, Fox G, Cullen P, Schulte H, Willett D, Grundy SM. Harmonizing the definition of the metabolic syndrome: comparison of the criteria of the Adult Treatment Panel III and the International Diabetes Federation in United States American and European populations. American Journal of Cardiology. 2007; 99:541-548. [PubMed: 17293200]

Barter P, Gotto AM, LaRosa JC, Maroni J, Szarek M, Grundy SM, Kastelein JJP, Bittner V, Fruchart J-C. Treating to New Targets, I. HDL cholesterol, very low levels of LDL cholesterol, and cardiovascular events. New England Journal of Medicine. 2007; 357:1301-1310. [PubMed: 17898099]

Bobes J, Arango C, Aranda P, Carmena R, Garcia-Garcia M, Rejas J, Group CSC. Cardiovascular and metabolic risk in outpatients with schizophrenia treated with antipsychotics: results of the CLAMORS Study. Schizophrenia Research. 2007; 90:162-173. [PubMed: 17123783]

Bushe C, Holt R. Prevalence of diabetes and glucose intolerance in patients with schizophrenia. British Journal of Psychiatry. 2004; 184:67-71. 
Cohn T, Prud'homme D, Streiner D, Kameh H, Remington G. Characterizing coronary heart disease risk in chronic schizophrenia: high prevalence of the metabolic syndrome. Canadian Journal of Psychiatry - Revue Canadienne de Psychiatrie. 2004; 49:753-760. [PubMed: 15633853]

De Hert MA, van Winkel R, van Eyck D, Hanssens L, Wampers M, Scheen A, Peuskens J. Prevalence of the metabolic syndrome in patients with schizophrenia treated with antipsychotic medication. Schizophrenia Research. 2006; 83:87-93. [PubMed: 16481149]

de Vegt F, Dekker JM, Jager A, Hienkens E, Kostense PJ, Stehouwer CD, Nijpels G, Bouter LM, Heine RJ. Relation of impaired fasting and postload glucose with incident type 2 diabetes in a Dutch population: The Hoorn Study. JAMA. 2001; 285:2109-2113. [PubMed: 11311100]

Dixon WJ. Simplified estimation from censored normal samples. Annals of Mathematical Statistics. 1960; 31:385-391.

Expert Panel on Detection, Evaluation and Treatment of High Blood Cholesterol in Adults. Executive Summary of The Third Report of The National Cholesterol Education Program (NCEP) Expert Panel on Detection, Evaluation, And Treatment of High Blood Cholesterol In Adults (Adult Treatment Panel III). JAMA. 2001; 285:2486-2497. [PubMed: 11368702]

Ford ES. The metabolic syndrome and mortality from cardiovascular disease and all-causes: findings from the National Health and Nutrition Examination Survey II Mortality Study. Atherosclerosis. 2004; 173:309-314. [PubMed: 15064107]

Girman CJ, Dekker JM, Rhodes T, Nijpels G, Stehouwer CDA, Bouter LM, Heine RJ. An exploratory analysis of criteria for the metabolic syndrome and its prediction of long-term cardiovascular outcomes: the Hoorn study. American Journal of Epidemiology. 2005; 162:438-447. [PubMed: 16076828]

Goff DC, Sullivan L, McEvoy JP, Meyer JM, H.A N, Daumit G, Lamberti S, D'Agnostino RB, Stroup TS, Lieberman JA. A comparison of ten-year cardiac risk estimates in schizophrenia patients from the CATIE Study and matched controls. Schizophrenia Research. 2005; 80:45-53. [PubMed: 16198088]

Grundy SM, Brewer B, Cleeman JI, Smith SC, Lenfant C. Definition of metabolic syndrome: report of the National Heart, Lung, and Blood Institute/American Heart Association conference on scientific issues related to definition. Circulation. 2004; 109:433-438. [PubMed: 14744958]

Guzder RN, Gatling W, Mullee MA, Byrne CD. Impact of metabolic syndrome criteria on cardiovascular disease risk in people with newly diagnosed type 2 diabetes. Diabetologia. 2006; 49:49-55. [PubMed: 16341841]

Hagg S, Lindblow Y, Mjorndal T, Adolfsson R. High prevalence of the metabolic syndrome among a Swedish cohort of patients with schizophrenia. International Clinical Psychopharmacology. 2006; 21:93-98. [PubMed: 16421460]

Henderson DC, Copeland PM, Borba CP, Daley TB, Nguyen DD, Cagliero E, Evins AE, Zhang H, Hayden DL, Freudenreich O, Cather C, Schoenfeld DA, Goff DC. Glucose metabolism in patients with schizophrenia treated with olanzapine or quetiapine: a frequently sampled intravenous glucose tolerance test and minimal model analysis. Journal of Clinical Psychiatry. 2006; 67:789797. [PubMed: 16841629]

Henderson DC, Nguyen DD, Copeland PM, Hayden DL, Borba CP, Louie PM, Freudenreich O, Evins AE, Cather C, Goff DC. Clozapine, diabetes mellitus, hyperlipidemia and cardiovascular risks and mortality: results of a 10-year naturalistic study. Psychiatry. 2005; 66:1116-1121.

Houseknecht KL, Robertson AS, Zavadoski W, Gibbs EM, Johnson DE, Rollema H. Acute effects of atypical antipsychotics on whole body insulin resistance in rats: implications for adverse metabolic effects. Neuropsychopharmacology. 2007; 32:289-297. [PubMed: 17035934]

Jeppesen J, Hein HO, Suadicani P, Gyntelberg F. Triglyceride concentration and ischemic heart disease: an eight-year follow-up in the Copenhagen Male Study [see comments] [published erratum appears in Circulation 1998 May 19;97(19):1995] [see comments]. Circulation. 1998; 97:1029-1036. [PubMed: 9531248]

Kahn R, Buse J, Ferrannini E, Stern M. The Metabolic Syndrome: time for a critical appraisal. Diabetes Care. 2005; 28:2289-2304. [PubMed: 16123508]

Lieberman JA, Stroup TS, McEvoy JP, Swartz MS, Rosenheck RA, Perkins DO, Keefe RSE, Davis SM, Davis CE, Lebowitz BD, Severe J, Hsiao JK. Effectiveness of antipsychotic drugs in patients 
with chronic schizophrenia. New England Journal of Medicine. 2005; 353:1209-1223. [PubMed: 16172203]

Lorenzo C, Williams K, Hunt KJ, Haffner SM. The National Cholesterol Education Program - Adult Treatment Panel III, International Diabetes Federation, and World Health Organization definitions of the metabolic syndrome as predictors of incident cardiovascular disease and diabetes. Diabetes Care. 2007; 30:8-13. [PubMed: 17192325]

Marder SR, Essock SM, Miller AL, Buchanan RW, Casey DE, Davis JM, Kane JM, Lieberman JA, Schooler NR, Covell N, Stroup S, Weissman EM, Wirshing DA, Hall CS, Pogach L, Pi-Sunyer X, Bigger JT Jr, Friedman A, Kleinberg D, Yevich SJ, Davis B, Shon S. Physical health monitoring of patients with schizophrenia. American Journal of Psychiatry. 2004; 161:1334-1349. [PubMed: 15285957]

Mayer-Davis EJ, Levin S, Bergman RN, D'Agostino RB Jr, Karter AJ, Saad MF. Insulin Resistance Atherosclerosis, S. Insulin secretion, obesity, and potential behavioral influences: results from the Insulin Resistance Atherosclerosis Study (IRAS). Diabetes/Metabolism Research Reviews. 2001; 17:137-145.

McEvoy JP, Meyer JM, Nasrallah HA, Goff DC, Davis SM, Sullivan L, Meltzer HY, Hsiao J, Stroup TS, Lieberman JA. Prevalence of the metabolic syndrome in patients with schizophrenia: baseline results from the Clinical Antipsychotic Trials of Intervention Effectiveness (CATIE) Schizophrenia Trial and comparison with national estimates from NHANES III. Schizophrenia Research. 2005; 80:19-32. [PubMed: 16137860]

McLaughlin T, Abbasi F, Cheal K, Chu J, Lamendola C, Reaven G. Use of metabolic markers to identify overweight individuals who are insulin resistant.[see comment][summary for patients in Ann Intern Med. 2003 Nov 18;139(10):I16; PMID: 14623638]. Annals of Internal Medicine. 2003; 139:802-809. [PubMed: 14623617]

Meyer JM. A retrospective comparison of weight, lipid, and glucose changes between risperidone-and olanzapine-treated inpatients: metabolic outcomes after 1 year. Journal of Clinical Psychiatry. 2002; 63:425-433. [PubMed: 12019668]

Meyer JM, Koro CE. The effects of antipsychotic therapy on serum lipids: a comprehensive review. Schizophrenia Research. 2004; 70:1-17. [PubMed: 15246458]

Meyer, JM.; Nasrallah, HA. Medical Illness and Schizophrenia. Washington, D.C.: American Psychiatric Press, Inc.; 2003. p. 254

Newcomer JW. Second-generation (atypical) antipsychotics and metabolic effects: a comprehensive literature review. CNS Drugs. 2005; 19:1-95. [PubMed: 15998156]

Reaven GM. Banting lecture 1988: role of insulin resistance in human disease. Diabetes. 1988; 37:1595-1607. [PubMed: 3056758]

Reaven GM. The metabolic syndrome: requiescat in pace. Clinical Chemistry. 2005; 51:931-938. [PubMed: 15746300]

Ridker PM, Buring JE, Cook NR, Rifai N. C-reactive protein, the metabolic syndrome, and risk of incident cardiovascular events: an 8-year follow-up of 14719 initially healthy American women. Circulation. 2003; 107:391-397. [PubMed: 12551861]

Saari KM, Lindeman SM, Viilo KM, Isohanni MK, Jarvelin M-R, Lauren LH, Savolainen MJ, Koponen HJ. A 4-fold risk of metabolic syndrome in patients with schizophrenia: the Northern Finland 1966 Birth Cohort Study. Journal of Clinical Psychiatry. 2005; 66:559-563. [PubMed: 15889940]

Saha S, Chant D, McGrath J. A systematic review of mortality in schizophrenia. Archives of General Psychiatry. 2007; 64:1123-1131. [PubMed: 17909124]

Sattar N, Gaw A, Scherbakova O, Ford I, O'Reilly DSJ, Haffner SM, Isles C, Macfarlane PW, Packard CJ, Cobbe SM, Shepherd J. Metabolic syndrome with and without C-reactive protein as a predictor of coronary heart disease and diabetes in the West of Scotland Coronary Prevention Study.[see comment]. Circulation. 2003; 108:414-419. [PubMed: 12860911]

Snijder MB, Visser M, Dekker JM, Seidell JC, Fuerst T, Tylavsky F, Cauley J, Lang T, Nevitt M, Harris TB. The prediction of visceral fat by dual-energy X-ray absorptiometry in the elderly: a comparison with computed tomography and anthropometry. International Journal of Obesity \& 
Related Metabolic Disorders: Journal of the International Association for the Study of Obesity. 2002; 26:984-993. [PubMed: 12080454]

Srisurapanont M, Likhitsathian S, Boonyanaruthee V, Charnsilp C, Jarusuraisin N. Metabolic syndrome in Thai schizophrenic patients: a naturalistic one-year follow-up study. BMC Psychiatry. 2007; 7:14. [PubMed: 17448257]

Stroup TS, McEvoy JP, Swartz MS, Byerly MJ, Glick ID, Canive JM, McGee MF, Simpson GM, Stevens MC, Lieberman JA. The National Institute of Mental Health Clinical Antipsychotic Trials of Intervention Effectiveness (CATIE) project: schizophrenia trial design and protocol development. Schizophrenia Bulletin. 2003; 29:15-31. [PubMed: 12908658]

Troisi RJ, Cowie CC, Harris MI. Diurnal variation in fasting plasma glucose: implications for diagnosis of diabetes in patients examined in the afternoon. JAMA. 2000; 284:3157-3159. [PubMed: 11135780]

Wannamethee SG, Shaper AG, Lennon L, Morris RW. Metabolic syndrome vs Framingham risk score for prediction of coronary heart disease, stroke, and type 2 diabetes mellitus. Archives of Internal Medicine. 2005; 165:2644-2650. [PubMed: 16344423]

Weiden PJ, Newcomer JW, Loebel A, Yang R, Lebovitz H. Long-term changes in weight and plasma lipids during maintenance treatment with ziprasidone. Neuropsychopharmacology advance online publication. 2007 Jul 18.:1-10. 


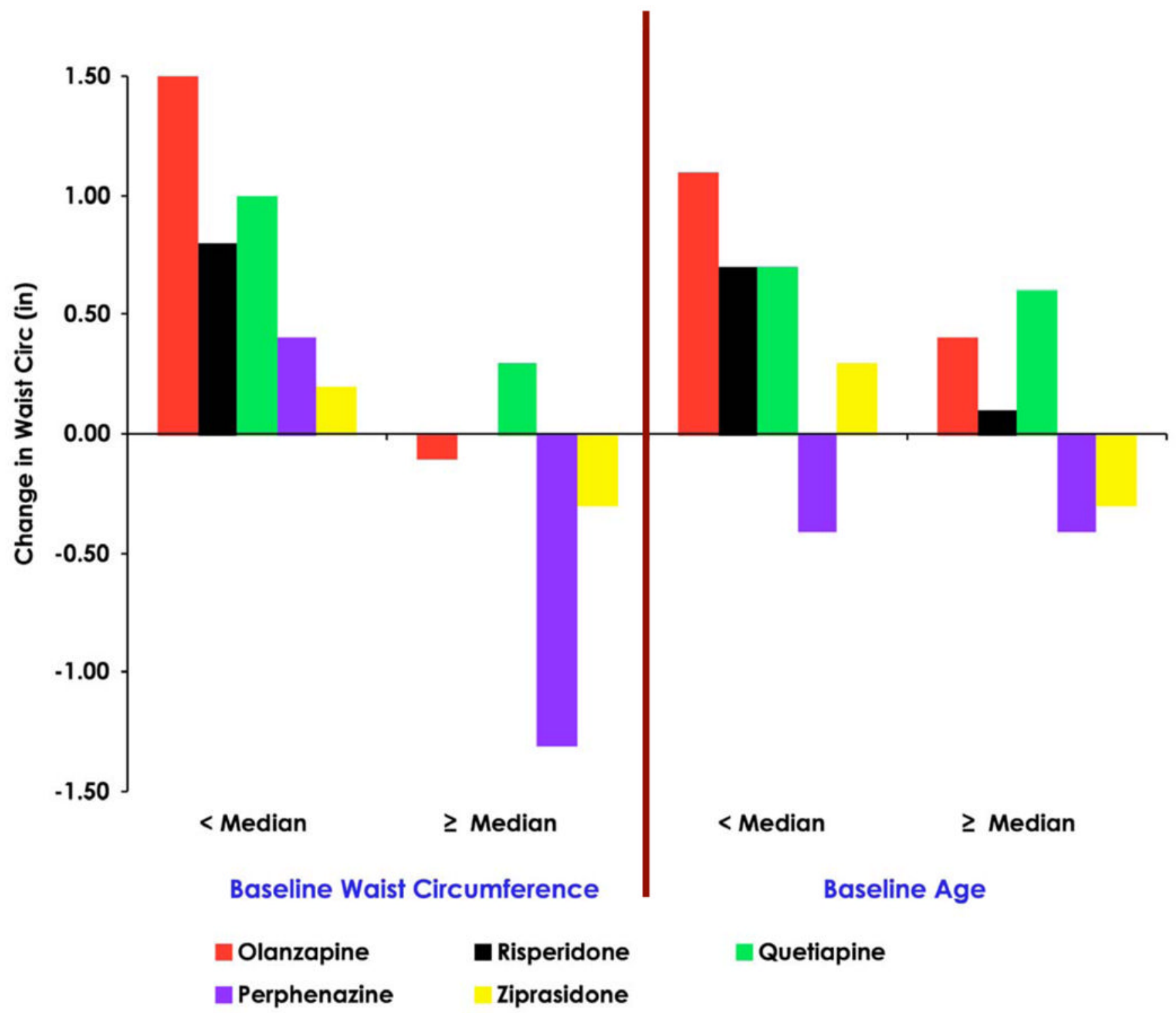

Figure 1.

Association Between Baseline Waist Circumference and Age and Adjusted 3-Month Changes in Waist Circumference 


\section{Table 1}

NCEP-Derived Diagnostic Criteria for the Metabolic Syndrome ( $\geq 3$ criteria must be present to establish diagnosis)(Grundy et al., 2004)

\begin{tabular}{|ll|}
\hline RISK FACTOR & DEFINING MEASURE \\
\hline Abdominal obesity & $>40$ inches \\
Men & $>35$ inches \\
Women & $\geq 150 \mathrm{mg} / \mathrm{dL}$ \\
\hline Fasting Triglycerides & $<40 \mathrm{mg} / \mathrm{dL}$ \\
\hline High Density Lipoprotein $($ HDL $)$ & $<50 \mathrm{mg} / \mathrm{dL}$ \\
Men & $\geq 130 / 85 \mathrm{~mm}$ Hg \\
Women & or on antihypertensive medication \\
\hline Blood Pressure & $\geq 100 \mathrm{mg} / \mathrm{dL}$ \\
& or on insulin or hypoglycemic medication \\
\hline
\end{tabular}


Table 2

Baseline Demographics of the Fasting Subject Cohort, the All Classifiable Subject Cohort, and All Subjects in CATIE Phase 1

\begin{tabular}{lccc}
\hline Parameter & Fasting Cohort & All Classifiable Cohort & All Subjects \\
\hline Age & $40.3(\mathrm{n}=281)$ & $40.9(\mathrm{n}=660)$ & $41.1(\mathrm{n}=933)$ \\
Gender (\% Male) & $77.9 \%(\mathrm{n}=281)$ & $74.9 \%(\mathrm{n}=660)$ & $74.0 \%(\mathrm{n}=933)$ \\
Race (\% White) & $65.5 \%(\mathrm{n}=281)$ & $60.1 \%(\mathrm{n}=659)$ & $61.2 \%(\mathrm{n}=932)$ \\
Ethnicity (\% Hispanic) & $11.7 \%(\mathrm{n}=281)$ & $10.9 \%(\mathrm{n}=660)$ & $11.7 \%(\mathrm{n}=933)$ \\
Years Since First Antipsychotic Treatment & $14.0(\mathrm{n}=271)$ & $14.4(\mathrm{n}=636)$ & $14.5(\mathrm{n}=899)$ \\
Systolic BP (mm Hg) & $124.3(\mathrm{n}=278)$ & $124.6(\mathrm{n}=658)$ & $124.9(\mathrm{n}=924)$ \\
Diastolic BP (mm Hg) & $79.6(\mathrm{n}=278)$ & $78.9(\mathrm{n}=658)$ & $79.0(\mathrm{n}=924)$ \\
Waist Circumference (in) & $39.0(\mathrm{n}=276)$ & $38.9(\mathrm{n}=654)$ & $39.5(\mathrm{n}=914)$ \\
Body Mass Index $\left(\mathbf{k g} / \mathbf{m}^{\mathbf{2}}\right)$ & $29.5(\mathrm{n}=278)$ & $29.3(\mathrm{n}=653)$ & $30.0(\mathrm{n}=923)$ \\
HDL (mg/dL) & $43.8(\mathrm{n}=281)$ & $44.7(\mathrm{n}=660)$ & $43.5(\mathrm{n}=891)$ \\
\hline
\end{tabular}

Note: Comparison of the fasting cohort with nonfasting subjects revealed no significant between group differences for any parameter. 


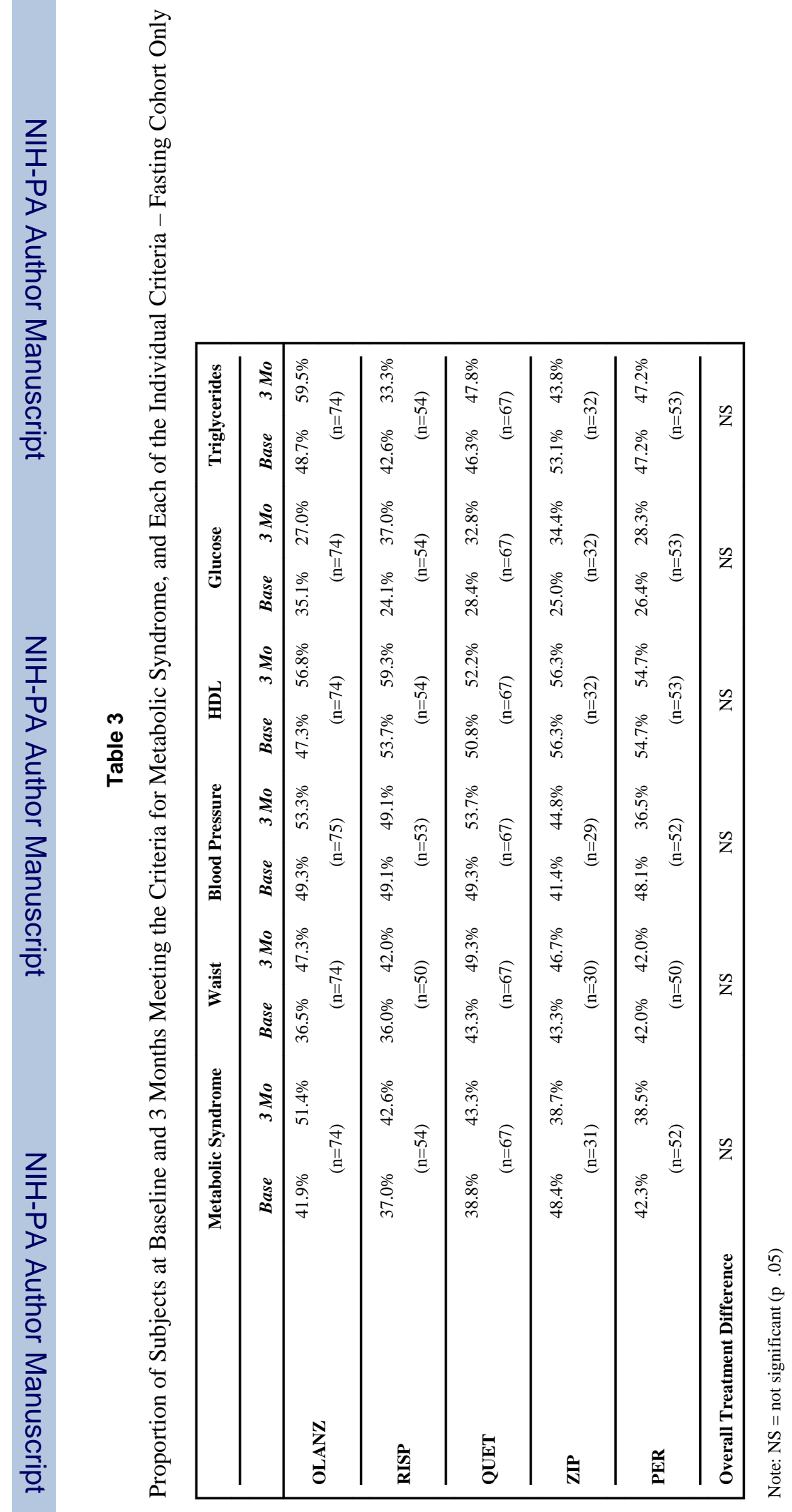


Table 4

Proportion of Subjects at Baseline and 3 Months Meeting the Criteria for Metabolic Syndrome - All Classifiable Subjects

\begin{tabular}{|lcc|}
\hline & \multicolumn{2}{c|}{ Metabolic Syndrome } \\
\hline OLANZAPINE & $34.8 \%$ & $\begin{array}{c}\text { Baseline } \\
(\mathrm{n}=164)\end{array}$ \\
\hline RISPERIDONE & $30.6 \%$ & $30.6 \%$ \\
\hline & & $(\mathrm{n}=147)$ \\
\hline QUETIAPINE & $37.8 \%$ & $37.1 \%$ \\
& & $(\mathrm{n}=143)$ \\
\hline ZIPRASIDONE & $37.7 \%$ & $29.9 \%$ \\
& & $(\mathrm{n}=77)$ \\
\hline PERPHENAZINE & $37.2 \%$ & $38.0 \%$ \\
\hline Overall Treatment Difference & & $(\mathrm{n}=129)$ \\
\hline
\end{tabular}

${ }^{\dagger}$ Change from baseline to 3 months in proportion of subjects meeting criteria for metabolic syndrome is greater for olanzapine than for ziprasidone $(\mathrm{p}=0.001)$ among all classifiable subjects. 


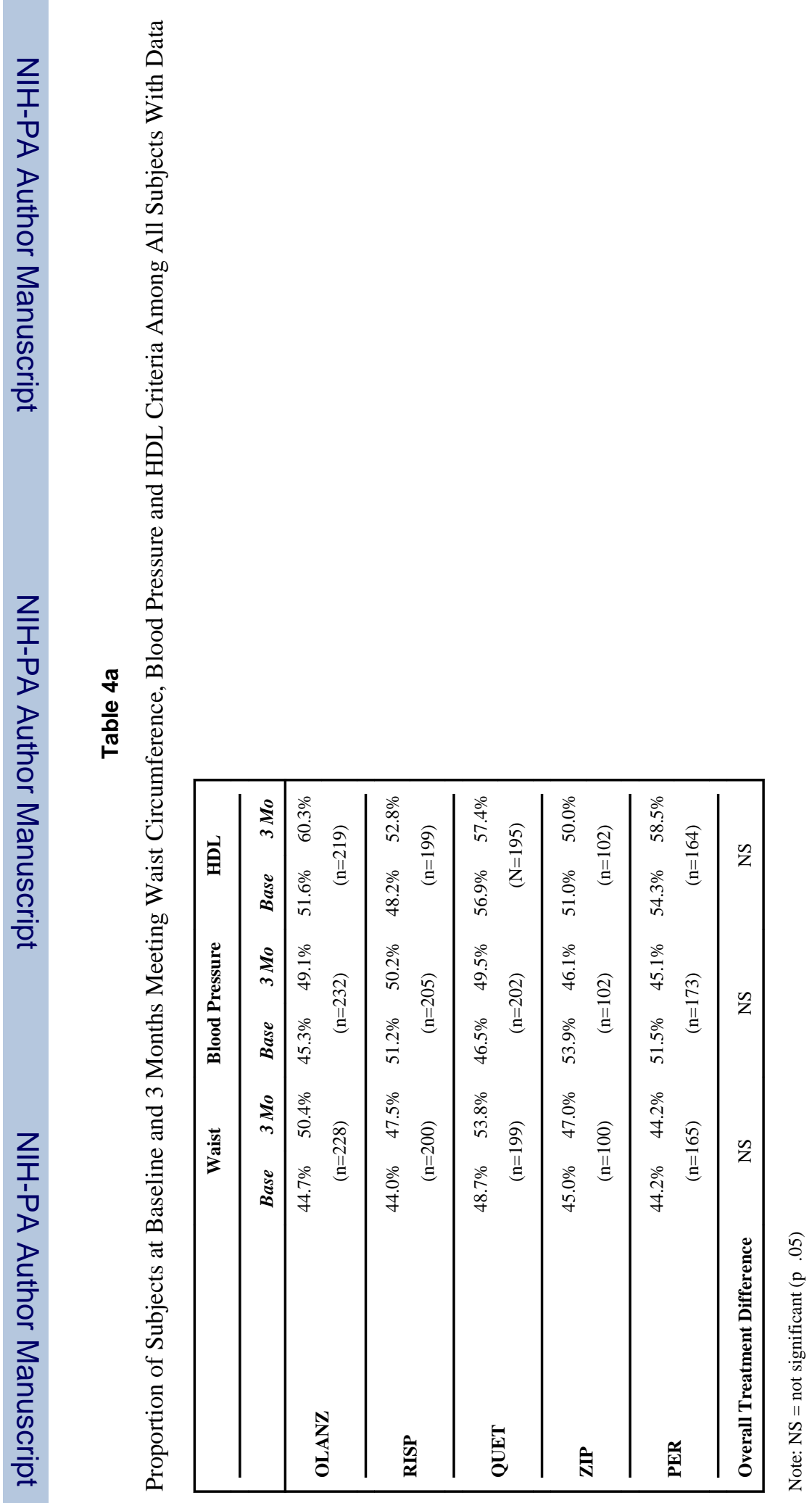

Schizophr Res. Author manuscript; available in PMC 2013 June 05. 


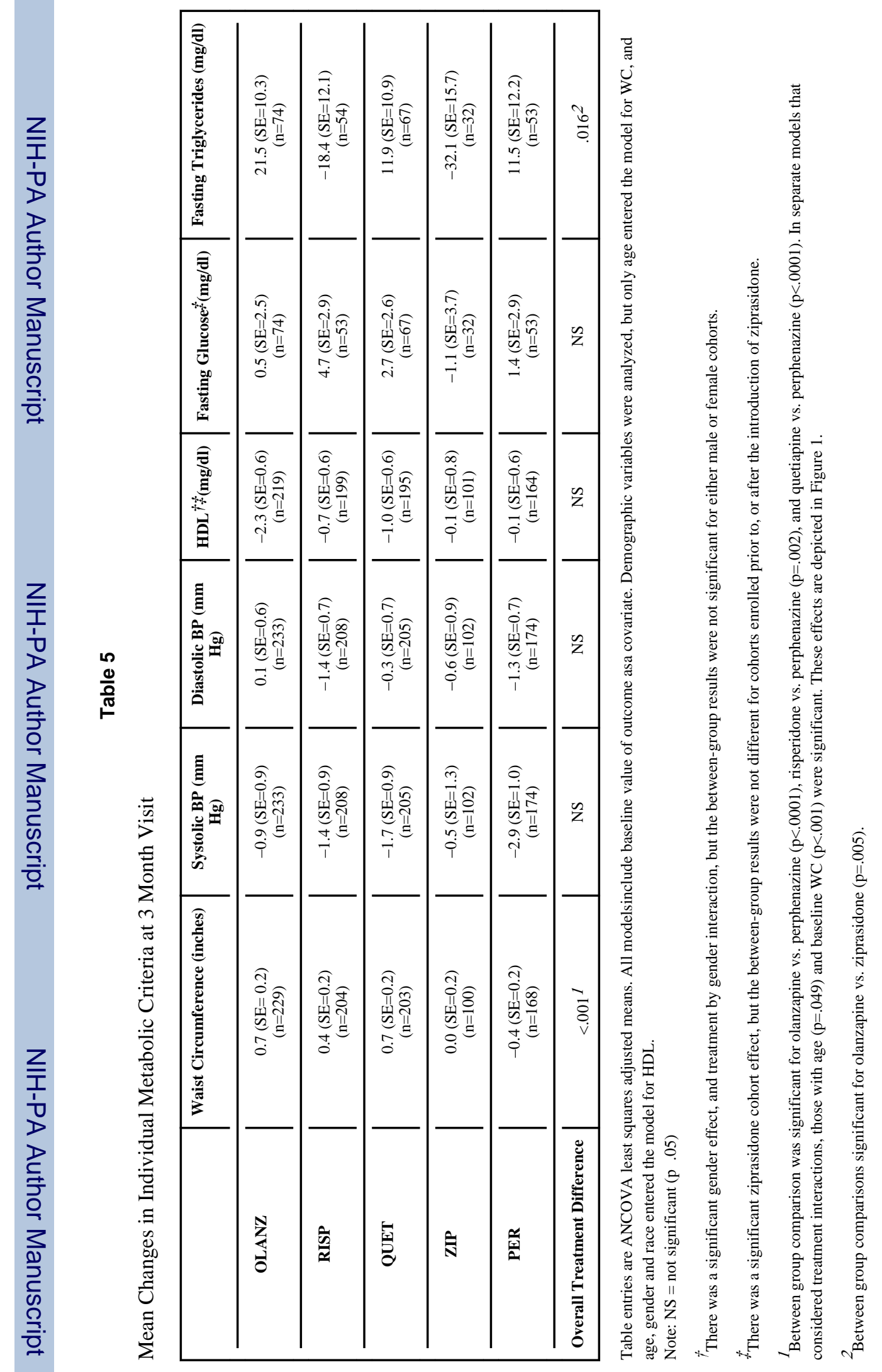




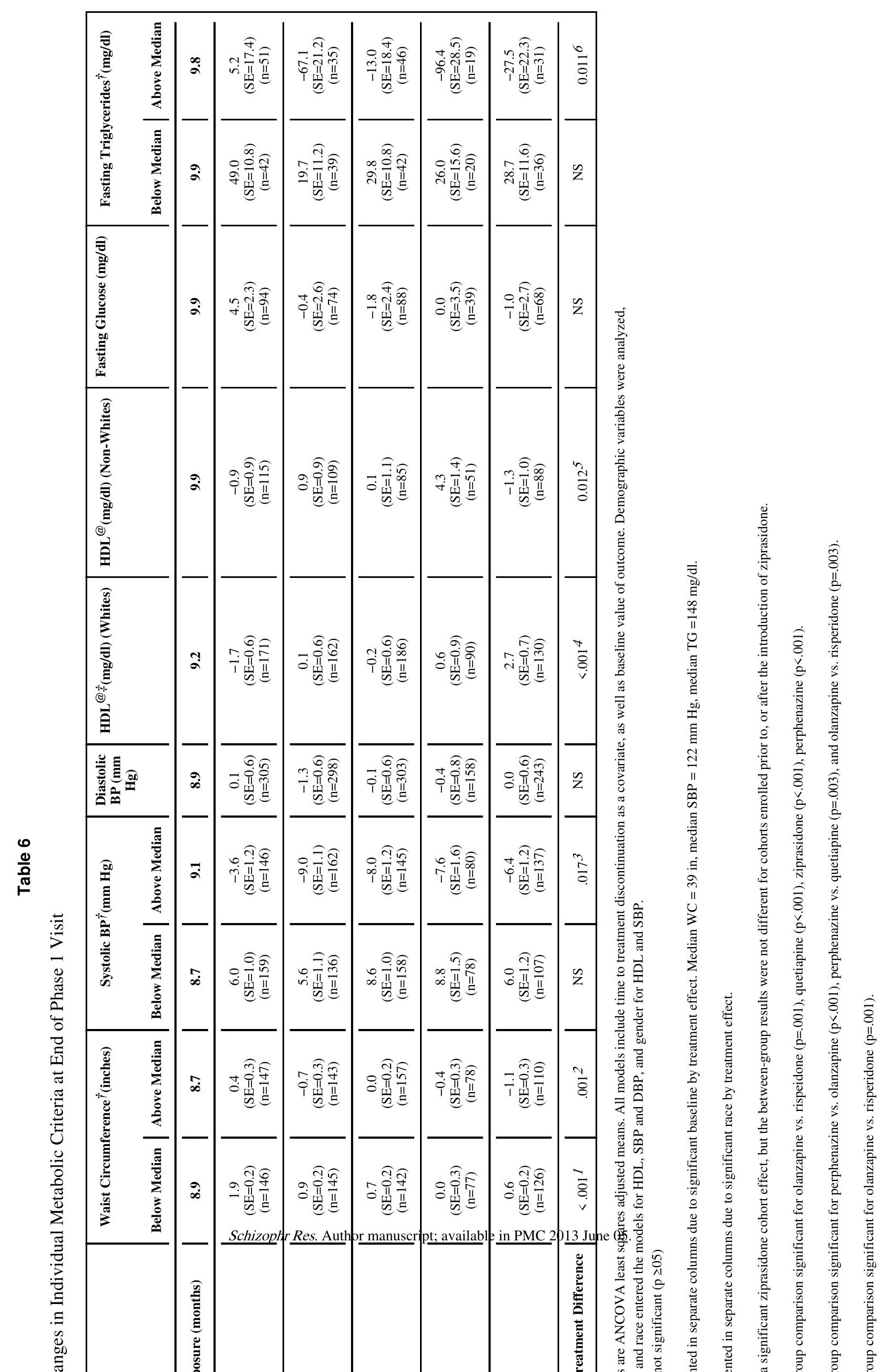




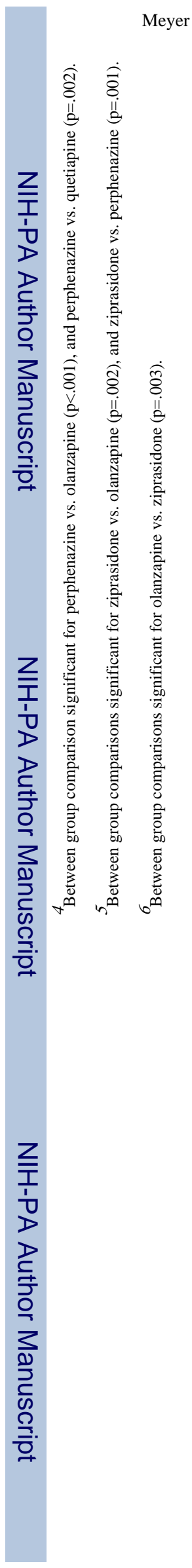

Schizophr Res. Author manuscript; available in PMC 2013 June 05. 